\title{
Spirometry in primary care case-identification, diagnosis and management of COPD
}

\section{*David Price ${ }^{a}$, Alan Crockett ${ }^{b}$, Mats Arnec, Bernard Garbe ${ }^{d}$, Rupert Jones $^{e}$, Alan Kaplan ${ }^{f}$, Arnulf Langhammer ${ }^{g}$, Siân Williams ${ }^{\mathrm{h}}$, Barbara Yawn}

a Centre for Academic Primary Care, University of Aberdeen, Scotland, UK

b Primary Care Respiratory Research Unit, The University of Adelaide, Adelaide, Australia

Respiratory Medicine and Allergology, Uppsala University, Uppsala, Sweden

d Vitalograph, Buckingham, UK

e PMS, RRU, Plymouth, UK

f Family Physician Airways Group of Canada, Ontario, Canada

g HUNT Research Centre, Norwegian University of Science and Technology, Verdal, Norway

h IPCRG, General Practice, Foresterhill Health Centre Westburn Road, Aberdeen, UK

Department of Family and Community Health, University of Minnesota, USA

Originally submitted 21st May 2008; resubmitted 17th October 2008; revised version received 16th July 2009; accepted 30th July 2009; online 18th August 2009

\begin{abstract}
Summary adherence.

(C) 2009 General Practice Airways Group. All rights reserved.

D Price et al. Prim Care Resp J 2009; 18(3): 216-223.

doi:10.4104/pcrj.2009.00055
\end{abstract}

Chronic obstructive pulmonary disease (COPD) is an important cause of morbidity and mortality worldwide, yet it remains significantly under-diagnosed. Systematic and opportunistic case-identification efforts in primary care, using questionnaires, careful assessment to identify symptoms, and follow-up spirometry, might improve diagnosis rates and enable earlier detection and management of COPD.

The aims of spirometry performed for case-identification purposes are to exclude those patients with symptoms but normal lung function and identify those who require more complete investigation for COPD, including 'diagnostic standard' spirometry. Among patients with a confirmed diagnosis of COPD, spirometry monitoring is useful in identifying those with rapid deterioration in lung function who require further assessment. Spirometry in primary care can also support patient education and may encourage smoking cessation and treatment

Keywords chronic obstructive pulmonary disease, spirometry, case-identification, primary care, diagnosis

\section{See linked editorial by Jenkins on pg 128}

\section{Introduction}

Chronic lung disease - predominantly asthma and chronic obstructive pulmonary disease (COPD) - is recognised as a significant cause of morbidity and mortality worldwide. The prevalence of COPD and its associated burden of disease is predicted to increase during the next 20 years, mainly due to population ageing and the global smoking epidemic.

In many regions, a trend has emerged towards increased primary care-based management of chronic respiratory diseases, with the aims of enabling earlier diagnosis, increasing patients' access to care within their community, reducing the overwhelming burden on hospital facilities, and better integrating care provided by different health services. Spirometry enables the primary care health professional to make an objective measurement of airflow limitation and the degree to which it is reversible, and is an important tool for accurate diagnosis and effective management of chronic respiratory diseases including asthma and COPD. ${ }^{1-8}$ However, spirometry remains underused in primary care. ${ }^{9,10}$ Barriers to performing spirometry in community settings include lack of access to calibrated spirometers, inadequate training in performing spirometry, lack of quality-control systems to ensure accurate results, and inadequate interpretation skills among health professionals performing the test. ${ }^{10,11}$

\footnotetext{
* Corresponding author: Professor David Price, Centre of Academic Primary Care, University of Aberdeen, Foresterhill Health Centre, Westburn Road, Aberdeen, AB25 2AY, UK. Tel: +44 (0)1224 554588 Fax: +44 (0)1224 840683 E-mail: respiratoryresearch@gmail.com
} 
The International Primary Care Respiratory Group (IPCRG) Subcommittee on Spirometry met recently to develop recommendations for the appropriate use of spirometry in the diagnosis and management of COPD in primary care, and to consider how primary care doctors might be better equipped to use this valuable clinical tool. Consensus among the writing group was developed over an 18-month discussion period that included further debate during two meetings of the IPCRG Research Subcommittee and four teleconferences.

The IPCRG's goals for spirometry in primary care are to improve operator skills to achieve an acceptable technical standard and to improve clinicians' skills in interpreting test results in the context of the patient's signs and symptoms. The subcommittee identified the following as key steps towards achieving these goals:

- defining the roles of spirometry in case-identification, diagnosis, disease monitoring and patient education in COPD

- setting standards for 'diagnostic spirometry'

- setting spirometry standards for COPD case-identification and disease monitoring

- developing training and certification requirements for spirometry in primary care.

In view of the limitations of current evidence, the IPCRG aims to stimulate debate and challenge current thinking about effective COPD diagnosis and management in primary care. This has been undertaken within the context of current evidence-based international guidelines for the management and diagnosis of COPD. Hence, we have not attempted to reexamine these evidence-based statements.

\section{COPD case-identification}

COPD remains significantly under-diagnosed, ${ }^{12}$ with diagnosis commonly missed or delayed until disease is advanced. A growing body of evidence suggests that early detection of airflow limitation and intervention for smoking cessation can delay lung function decline, reduce the burden of COPD symptoms, and improve patients' quality of life. ${ }^{12-14}$ Therefore, widespread screening would have the potential to detect the disease at an early stage and improve outcomes through smoking cessation and other proven interventions. ${ }^{1,6,13}$ However, at present there is insufficient evidence to recommend mass spirometry screening for asymptomatic people. Further research is needed to clarify the benefits and appropriate methods of screening for COPD. ${ }^{15-17}$

Targeted, systematic case-identification in primary care has been proposed as a strategy to improve diagnosis rates and enable early detection and management, including aggressive smoking cessation efforts. ${ }^{12,18,19}$ Primary care encounters also enable opportunistic preliminary assessment of people who present with respiratory symptoms and risk
Figure 1. An approach to COPD case-identification in primary care.

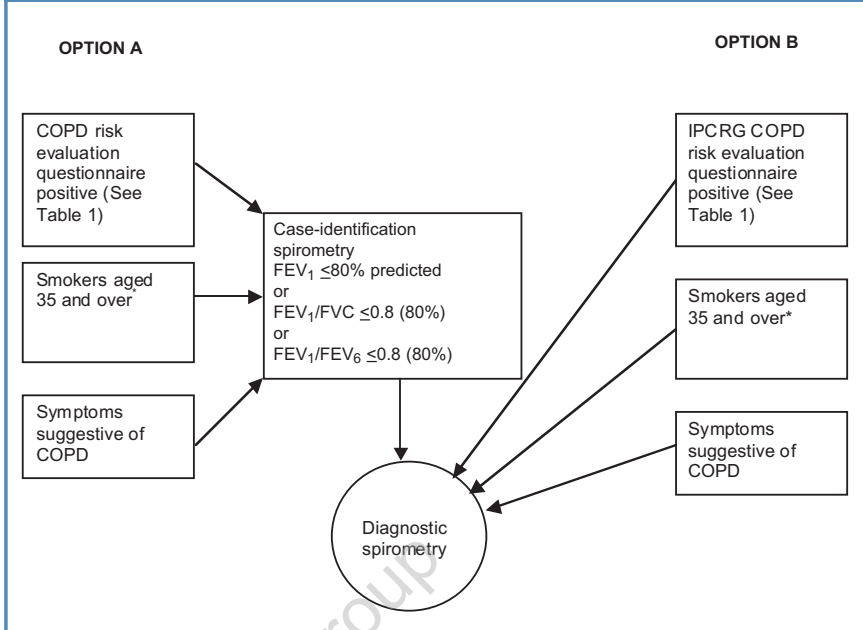

*Patients aged 30 and over if high risk (e.g. family history of COPD, occupational or environmental risk, smoker since childhood)

The possibility of COPD should be considered in all patients with a long-term history of exposure to risk factors, all those with a clinical history suggestive of COPD, and all those with a positive questionnaire result. Multiple protocols for investigating the possibility of COPD in at-risk patients are appropriate in primary care, depending on the setting and resources available. Where a full spirometry service is readily available, immediate diagnostic spirometry might be appropriate. In other settings, opportunistic case-identification spirometry may enable the primary care health professional to identify those who require further investigation. Regardless of the initial steps taken to rule out COPD, patients with abnormal findings on spirometry or symptom questionnaire will require full diagnostic spirometry, performed to internationally acceptable standards. Diagnostic spirometry must include post-bronchodilator testing.

factors such as smoking. The IPCRG currently recommends that all patients over 35 years old should be evaluated for their risks of developing COPD (see Figure 1), either by taking a history using validated screening questionnaires based on a combination of risk factors and symptoms (see Table 1), ${ }^{20}$ 'case-identification' spirometry as described below, or standard diagnostic spirometry. Diagnostic spirometry should be offered to patients who have symptoms and risk factors, a positive screening questionnaire, or those who are not excluded by case-identification spirometry.

The aims of spirometry performed for case-identification purposes are to exclude those with normal lung function and identify those who require more complete investigation for COPD. In this context, spirometry protocols and standards will differ from those of spirometry performed for the purpose of achieving a definitive diagnosis. ${ }^{21}$ For case-identification, it is acceptable to perform a less specific but relatively sensitive test - that is, to proceed by exclusion. Suitable spirometry parameters are forced expiratory volume in one second $\left(F E V_{1}\right)$, ratio of $F E V_{1}$ to forced vital capacity (FVC), and ratio of $\mathrm{FEV}_{1}$ to forced expiratory volume in 6 seconds $\left(\mathrm{FEV}_{6}\right)$. The IPCRG proposes the following spirometry criteria for 


\begin{tabular}{|c|c|c|}
\hline Patient characteristic & Value & Score \\
\hline \multirow[t]{4}{*}{ Age (years) } & $35-49$ & 0 \\
\hline & $50-59$ & 4 \\
\hline & $60-69$ & 8 \\
\hline & $\geq 70$ & 10 \\
\hline \multirow[t]{4}{*}{ Smoking (pack-years)* } & $0-14$ & 0 \\
\hline & $15-24$ & 2 \\
\hline & $25-49$ & 3 \\
\hline & $\geq 50$ & 7 \\
\hline \multirow[t]{3}{*}{ Body mass index $\left(\mathrm{kg} / \mathrm{m}^{2}\right)$} & $<25.4$ & 5 \\
\hline & $25.4-29.7$ & 1 \\
\hline & $>29.7$ & 0 \\
\hline \multirow{2}{*}{$\begin{array}{l}\text { Presence of cough that is affected } \\
\text { by weather }\end{array}$} & Yes & 3 \\
\hline & No & 0 \\
\hline \multirow[t]{2}{*}{ Sputum production in absence of a cold } & Yes & 3 \\
\hline & No & 0 \\
\hline \multirow{2}{*}{$\begin{array}{l}\text { Sputum production when first waken } \\
\text { each morning }\end{array}$} & Yes & 0 \\
\hline & No & 3 \\
\hline \multirow[t]{2}{*}{ Wheezing } & Sometimes/often & 4 \\
\hline & Never & 0 \\
\hline \multirow[t]{2}{*}{ History/presence of allergies } & Yes & 0 \\
\hline & No & \\
\hline \multicolumn{3}{|c|}{$\begin{array}{l}\text { Adapted from reference } 20 \text { with permission } \\
\text { Available at http://www.theipcrg.org/resources/resources_diagnostics.php } \\
\text { *Average number of packs ( } 20 \text { cigarette) smoked per day multiplied by } \\
\text { number of years of smoking } \\
\text { Scoring: a total score of } 17 \text { or higher indicates increased risk that the person } \\
\text { has COPD. }\end{array}$} \\
\hline
\end{tabular}

identifying symptomatic patients in whom the possibility of COPD cannot be excluded and who therefore require further diagnostic assessment for COPD (where available):

- $\mathrm{FEV}_{1} \leq 80 \%$ predicted value

or

- $\mathrm{FEV}_{1} / \mathrm{FVC} \leq 0.8(80 \%)$

or

- $\mathrm{FEV}_{1} / \mathrm{FEV}_{6} \leq 0.8(80 \%)$

The IPCRG emphasises that these cut-points do not represent diagnostic standards for the presence of obstruction, but rather they serve as exclusion criteria. Patients with an $\mathrm{FEV}_{1}$ value $>80 \%$ predicted or an $\mathrm{FEV}_{1} / \mathrm{FVC}$ ratio $>0.8$, in the absence of symptoms, are unlikely to have COPD. The rationale for including a ratio of $\mathrm{FEV}_{1} / \mathrm{FVC}_{6}$ of $\leq$ 0.8 rather than 0.7 , and an $\mathrm{FEV}_{1}$ cut-point of $80 \%$, is that underestimation of either FVC or $\mathrm{FEV}_{6}$ can result in a relatively normal ratio. The IPCRG emphasises that 'case-identification' spirometry must not replace standard diagnostic spirometry, which must be performed according to internationally accepted standards set by the European Respiratory Society (ERS) and American Thoracic Society (ATS). ${ }^{15}$ In some primary care settings, this might involve referral to specialist spirometry services. The clinical context of symptoms and exposure to COPD risk factors must be considered for all patients with demonstrated airflow limitation, including the elderly.

\section{Diagnostic spirometry}

The IPCRG fully endorses international guidelines for the use of spirometry in the diagnosis of respiratory disease. Spirometry is a useful diagnostic tool in primary care, with major roles in distinguishing respiratory from non-respiratory causes in the investigation of shortness of breath, discriminating between reversible and non-reversible airflow limitation, and in making the diagnoses of COPD and asthma. Diagnostic spirometry should be conducted according to internationally agreed standards. ${ }^{15}$

Spirometry is an essential investigation to confirm the clinical diagnosis of COPD as well as a useful investigation in assessing severity. ${ }^{1,2,6}$ Spirometry is also an important investigation in confirming the clinical diagnosis of asthma and evaluating asthma severity and pattern of airflow limitation. .,7 $^{2}$

Diagnostic criteria for COPD set by the Global Initiative for Chronic Obstructive Lung Disease (GOLD) are based on the finding of an $\mathrm{FEV}_{1} / \mathrm{FVC}$ ratio less than 0.7 when measured after administration of an inhaled bronchodilator. ${ }^{1}$ However, it has been acknowledged that reduction in lung function due to ageing may affect the diagnostic accuracy of these measures in older patients. ${ }^{1}$ Criteria for the diagnosis of airflow limitation in the elderly are currently under review, and alternative cut-points, such as the bottom $5 \%$ of the normal population distribution for $\mathrm{FEV}_{1} / \mathrm{FVC}$ ratio by age category (i.e. 'lower limit of normal'), are being assessed by an international working group. ${ }^{1}$ Whilst this evidence has not yet been fully established in international guidelines, we have made our recommendations based on current guidance.

\section{Disease monitoring}

In addition to its diagnostic uses, spirometry is a valuable primary care clinical tool for monitoring some respiratory conditions. In patients with asthma, objective assessment of lung function by spirometry (or by using a peak flow meter) is an important component of the assessment of disease control, response to treatment, and the ongoing assessment of disease severity, as well as a useful tool in the investigation of acute episodes. ${ }^{5,7}$

In patients with COPD, spirometry has a limited role in assessing treatment response, because spirometric 
Figure 2. An approach to spirometry-based disease monitoring in primary care.

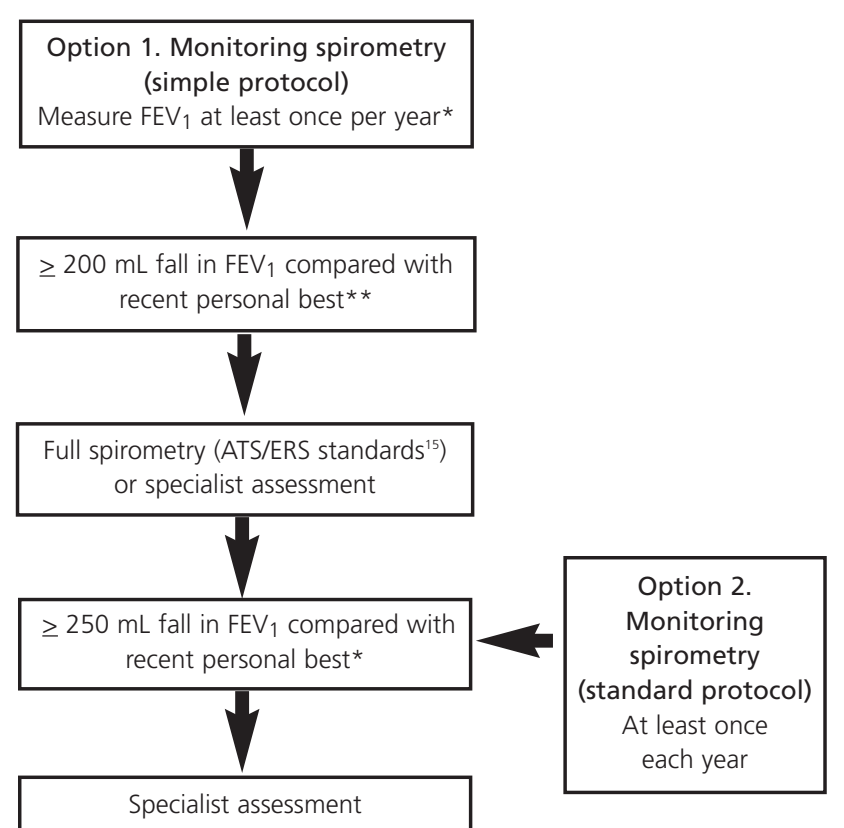

ATS/ERS: American Thoracic Society and European Respiratory Society

*Schedule spirometry when patient clinically stable (not during an exacerbation)

**Personal best measured during past 18 months during a period of clinical stability

parameters do not generally correlate well with disease severity or control as perceived by patients - although it may be more responsive in those with a lesser degree of lung function impairment.

Spirometry may have a more useful role in identifying patients with substantial deterioration in lung function who may require specialist assessment. Ideally, in line with international guidelines, spirometry performed to diagnostic standards should be repeated yearly for all patients with COPD and twice yearly for those with very severe disease. Since this is often not feasible in primary care practice, the IPCRG proposes that the following simple protocol could be used to identify patients with rapid deterioration in lung function who require further investigation:

- Measure FEV 1 annually during a period of clinical stability.

- If undertaken with a simple spirometer without a flow-volume loop, and the reading is $200 \mathrm{~mL}$ or more below the person's recent best result (recorded when clinically stable during the previous 18 months), perform or arrange full spirometry (Figure 2).

- A fall of $250 \mathrm{~mL}$ or more on spirometry performed to ATS/ERS diagnostic standards indicates the need for additional care (e.g. increased smoking cessation support and referral for radiography, assessment of alpha1antitrypsin and/or specialist care). These cut-points have been arbitrarily selected to allow for normal intraindividual lung function variability, operator variability and the limits of device accuracy.

Spirometric parameters are proving useful as components of risk scores for COPD such as the Body-Mass Index, Airflow Obstruction, Dyspnea, and Exercise Capacity (BODE) Index ${ }^{22}$ and the Dyspnoea Scale, Airflow Obstruction, Smoking Status and Exacerbations (DOSE) Index, which reliably predicts patient-centred outcomes including hospital admissions and use of after-hours medical services. ${ }^{23,24}$ In asthma, spirometric measures are included in comprehensive criteria for disease control, such as the Asthma Control Questionnaire. ${ }^{25}$ Spirometry is also used in the monitoring of some inhaled medications to detect medication-induced bronchospasm or inflammation.

Further research is needed to understand the relationship between COPD and common co-morbid conditions such as cardiovascular disease and diabetes, and to define the role of lung function monitoring. Pulmonary involvement in diabetes is increasingly reported, ${ }^{26-33}$ and may have important consequences if patients have co-morbid COPD. Routine spirometry to monitor lung function may therefore be useful in the care of patients with diabetes, particularly those who smoke. Vigorous smoking cessation intervention is central to primary care-based management of any chronic disease.

Discussing the spirometry result with the patient can support self-management education by encouraging smoking cessation, treatment adherence and other lifestyle modifications. ${ }^{34}$ These efforts can be reinforced by using tools such as the Fletcher-Peto plot of lung function decline in COPD due to smoking, ${ }^{35}$ the Primary Care Respiratory Calculator (developed by the University of Adelaide and available at http://doctorwidget.com), or "estimated lung age". 36

\section{Standards for spirometry in primary care}

spirometry performed after administration of a short-acting bronchodilator (ideally in conjunction with pre-bronchodilator readings) is essential to confirm irreversible airflow obstruction in the diagnosis of COPD.

\section{Device standards}

The IPCRG recommends that all spirometers used in primary care should be robust, easy to clean and calibrate, and have the capability to measure FEV $1, F V_{6}$ (alternatively FVC or VC), either estimated $\mathrm{FEV}_{1} / \mathrm{FEV}_{6}$ or $\mathrm{FEV}_{1} / \mathrm{FVC}$, and forced expiratory time (where FVC is used). Ability to measure FEV 1 accurately is an essential requirement because it is the most reliable parameter for assessing airflow limitation, is subject 
Table 2. Standards for spirometers used in primary care.

\begin{tabular}{l} 
Essential \\
\hline Measures mandatory parameters: \\
- $\mathrm{FEV}_{1}$ \\
- $\mathrm{FEV}_{6}$ or $\mathrm{FVC}$ \\
- $\quad$ Forced expiratory time \\
Complies with minimum $\mathrm{ATS} / \mathrm{ERS}$ technical criteria for acceptable \\
tests and session repeatability ${ }^{15}$ \\
Flow-volume loop and/or volume-time curve displayed during \\
the manoeuvre \\
Reliable and robust device (as demonstrated by in vivo studies) \\
Easy to perform an accuracy check \\
Simple cleaning and maintenance \\
Report on reproducibility of manoeuvres provided \\
Error report in clear and simple language, including suggestions \\
to improve technique
\end{tabular}

Optimal (in addition to essential standards)

Provides LLN for $\mathrm{FEV}_{1}, \mathrm{FVC}_{1}, \mathrm{FEV}_{1} / \mathrm{FEV}_{6}, \mathrm{FEV}_{1} / \mathrm{FVC}$ as well as predicted mean values

Software for estimation of $\mathrm{FEV}_{1}$ reversibility

Peak expiratory flow or forced expiratory time (as indicator of correct spirometry manoeuvre if no FVC or $\mathrm{FEV}_{6}$ is available to calculate extrapolated volume)

Links to other software including patient records

Error messages appear automatically in the following situations (as a minimum):

- Slow start - message (e.g. Blow hard and fast right from the start) triggered when back extrapolation volume $>150 \mathrm{~mL}$ or $5 \%$ (whichever greater) and/or time to PEF $>120$ milliseconds

- Cough detected during the first second of the forced expiration manoeuvre

- Premature stop - message (e.g. Keep blowing out for longer) triggered when a rapid cessation of flow detected or no plateau or FET $<6$ seconds $<3$ seconds for children under 1 years)

ATS/ERS: American Thoracic Society and European Respiratory Society Task Force; LLN: lower limit of normal (i.e. the bottom $5 \%$ of the normal distribution observed in the healthy reference population); PEF: peak expiratory flow

to low intra-individual variability, is the basis for reversibility tests, and is also important for disease staging. A reliable, precise and accurate measurement of $\mathrm{FEV}_{6}$ or $\mathrm{FVC}$ is essential too, since the ratio $\mathrm{FEV}_{1} / \mathrm{FVC}$ or $\mathrm{FEV}_{1} / \mathrm{FEV}_{6}$ is critical in determining airflow obstruction. Reference values for each parameter should be relevant to the local population.

Forced expiratory time is relevant only when attempting to avoid underestimation of FVC in adults. In patients with severe airflow obstruction, measurement of slow inspiratory vital capacity provides a better index of true vital capacity than FVC.

For spirometry to be clinically useful, the operator must have immediate access to feedback on the technical quality of the manoeuvre, either in the form of a clearly worded message or a visual display of volume-time curve and/or flow-volume loop during the manoeuvre. A graph of the volume-time curve and/or flow-volume loop should also be available after the test session. Before assessing the readings obtained, the operator should judge whether or not the manoeuvre was acceptable (e.g. rapid start of exhalation, free of significant artefact). Whichever method is used, the experience and dedication of the person administering the test is important in detecting and correcting manoeuvre errors.

Hand-held spirometers are acceptable for the purposes of case-identification or medical review in primary care. Table 2 sets out proposed standards for spirometers used in primary care for case identification and diagnosis of COPD, in world communities with differing access to spirometry equipment.

\section{Operator standards}

Primary care health professionals will require appropriate training and standards to enable them to use spirometry as an effective clinical tool. A number of IPCRG member organisations currently provide training and/or formal certification (see http://www.theipcrg.org/links/links_ copd.php).

Table 3 provides some suggested remedies for the most common errors in performing spirometry.

\section{Discussion}

Increased use of spirometry in primary care, performed to appropriate standards, is expected to increase rate of detection of COPD and enable earlier intervention (e.g. smoking cessation) with the aims of improving patients' health status, reducing the rate of lung function decline, ${ }^{36}$ and reducing the risk of adverse events such as exacerbations. While the use of spirometry in mass population screening remains controversial, ${ }^{16,37}$ its use in targeted caseidentification is feasible in most primary settings.

While there is little current evidence that patients would benefit from early diagnosis of asymptomatic COPD, earlier diagnosis of clinical COPD has several potential benefits. At present, patients with undiagnosed COPD experience significant symptoms and compromised quality of life. Many of these people also consult primary care physicians during exacerbations, and if not correctly diagnosed may end up being inappropriately treated. Once COPD is diagnosed, primary care doctors are well placed to manage and even prevent COPD exacerbations by applying evidence-based guidelines. Although as yet unproven, appropriate drug treatment might achieve a small reduction in the rate of decline of $\mathrm{FEV}_{1}{ }^{38}$

The potential benefits of early diagnosis of lung function 
Table 3. Common problems in performing spirometry and solutions.

\begin{tabular}{|c|c|}
\hline Problem type & Remedy \\
\hline $\begin{array}{l}\text { Technical skill } \\
\text { (e.g. early stops, lack of } \\
\text { maximal forced effort, slow } \\
\text { starts, coughs, interrupted } \\
\text { flow) }\end{array}$ & $\begin{array}{l}\text { - Training in use and interpretation (basic training sufficient for case-identification spirometry) } \\
\text { - } \text { operators should practice performing the manoeuvre to reinforce and improve skills, and act as control } \\
\text { - Automatic feedback and technical error messages from machine should be provided - ideally with } \\
\text { sound and in plain language (See Table 2) }\end{array}$ \\
\hline $\begin{array}{l}\text { Interpretation } \\
\text { (e.g. use of incorrect reference } \\
\text { values, lack of understanding } \\
\text { of spirometry principles, failure } \\
\text { to explain meaning of findings } \\
\text { to patient) }\end{array}$ & $\begin{array}{l}\text { - Use IPCRG opinion sheet available at http://www.theipcrg.org/resources/resources_diagnostics.php } \\
\text { - Turn off automatic interpretation and interpret from first principles } \\
\text { - Training: refresh skills and obtain regular feedback on quality of performance } \\
\text { - Financial incentives for practitioner to offset cost of training } \\
\text { - Use Primary Care Respiratory Calculator (available at http://doctorwidget.com) to show patient } \\
\text { personalised Fletcher-Peto curves }\end{array}$ \\
\hline
\end{tabular}

decline are currently under debate. While reviews undertaken by the US Agency for Healthcare Research and Quality (AHRQ) led to a recommendation against the use of spirometry for early detection of COPD in smokers - on the rationale that health benefits of early diagnosis would be unlikely to outweigh detrimental effects of false-positives other evidence suggests that the diagnosis of COPD increases patients' motivation to quit smoking. ${ }^{18}$ To date, no adequately powered study has addressed this question. While early diagnosis of symptomatic COPD may not markedly reduce smoking rates in the short term, it is a desirable clinical goal to enable symptom relief and exacerbation prevention, case management and treatment planning to prevent further organ damage, consistent with the current emphasis on early diagnosis for other chronic diseases. In some health systems, including that of the UK, opportunistic spirometry to detect COPD is likely to be cost effective. ${ }^{6}$.

There are several limitations to achieving highly acceptable and reproducible spirometry in primary care. This situation has led to debate as to whether 'softening' the stringent ATS/ERS spirometry criteria might make spirometry more accessible to primary care health professionals for the purpose of caseidentification at the point of consultation, in order to improve the rate of detection of COPD. ${ }^{39}$ The use of a targeted 'firstpass' case-identification strategy with relatively high sensitivity and relatively low specificity might be a reasonable approach for this purpose. However, it would not serve as an adequate diagnostic test. Regardless of strategies used for identifying at-risk patients, diagnostic spirometry should be performed consistent with ATS/ERS quality goals. Similarly, the IPCRG endorses international treatment guidelines.

We have proposed the $\mathrm{FEV}_{1} / \mathrm{FVC}$ ratio cut-point of 0.8 for case-identification spirometry in order to allow for patients who cannot perform a full FVC manoeuvre. While values above 0.8 are likely to rule out COPD, the use of the 0.8 ratio will, however, misclassify as high risk a proportion of patients without COPD. Within each health system, the acceptability of the false-positive rate will depend on whether the benefits of aggressive case-finding are judged to balance the costs of the subsequent diagnostic process, including specialist referral and further spirometry. The age range of the target population for case identification will also depend on local risk factors. In countries with low rates of long-term exposure to indoor smoke, it may be more appropriate to target smokers aged 45 and older.

Health systems could promote the uptake of spirometry through reimbursement incentives. In the UK, the Quality Outcomes Framework offers a model for increasing spirometry rates by providing payments to clinicians for spirometry performed for case identification, diagnosis and monitoring. In Belgium, primary care doctors are reimbursed for spirometry only if they have undergone specified training based on current guidelines and perform each spirometry procedure to pre-defined standards. It may also be appropriate for other health professionals, such as pharmacists, to participate in case identification among symptomatic smokers.

The case-identification strategy outlined here represents a new approach for primary care and must be tested through further research, particularly in the following areas:

- the costs and benefits of a population screening strategy for COPD

- the effects of a case-identification strategy on smoking cessation and patient wellbeing

- the cost-effectiveness of early identification of COPD

- the most feasible and efficient protocols for spirometry in primary care, including optimal cut-points for caseidentification spirometry and the optimal frequency of spirometric review

- appropriate normal values for age-groups and national 


\section{populations}

- whether the rate of $\mathrm{FEV}_{1}$ decline is an important predictor of the prognosis in COPD

- the value of FEV1 as a prognostic indicator for all-cause or cardiovascular mortality

- the correlation between inspiratory parameters, hyperinflation and symptoms in COPD

- the most effective methods of training primary care health professionals in spirometry and ensuring that these skills are maintained.

\section{Conflict of interest declarations}

DP either through his role at the University of Aberdeen or personally has received grants, honoraria or educational support from the following pharmaceutical companies as well as the UK NHS R\&D programme: 3M Pharmaceuticals, Abbot Laboratories, AstraZeneca, GlaxoSmithKline, Innovata Biomed, Ivax pharmaceuticals Ltd, Merck, Sharpe and Dohme, Medeva, Novartis, Roche, Schering Plough, Yamanouchi. He does not possess any pharmaceutical shares.

AJC has no conflict of interest to declare.

MA has no conflict of interest to declare.

BG is a salaried Executive Director of Vitalograph (Respiratory disease and services supplier).

RJ has no conflict of interest to declare.

AK has no conflict of interest to declare.

AL has no conflict of interest to declare.

SW is Executive Officer of the IPCRG that receives associate corporate membership and project support from a number of pharmaceutical companies. She is also a freelance health consultant and has worked for IMPRESS, a joint initiative between the GPIAG and British Thoracic Society that receives grants from a number of pharmaceutical companies.

BY has no conflict of interest to declare.

\section{Acknowledgements}

Johan Buffels, Niels Chavannes, Claus Justus, Miguel Roman Rodriguez, Tjard Schermer and Mike Thomas participated in discussions with the authors.

Samantha Louw provided administrative assistance. A professional medical writer (Jennifer Harman, Meducation Australia), assisted in drafting the manuscript. Vitalograph Limited provided a room for the initial authors' meeting, and Sherborne Gibbs Limited provided transcription services for this initial meeting.

\section{References}

Global Initiative for Chronic Obstructive Lung Disease (GOLD). Global strategy for the diagnosis, management and prevention of COPD. 2007

2. Bellamy D, Bouchard J, Henrichsen S, et al. International Primary Care Respiratory Group (IPCRG) Guidelines: management of chronic obstructive pulmonary disease (COPD). Prim Care Resp J 2006;15:48-57. http://dx.doi.org/10.1016/.jpcrj.2005.11.003

3. Levy ML, Fletcher M, Price DB, Hausen T, Halbert RJ, Yawn BP. International Primary Care Respiratory Group (IPCRG) Guidelines: diagnosis of respiratory diseases in primary care. Prim Care Resp J 2006;15:20-34. http://dx.doi.org/10.1016/j.pcrj.2005.10.004

4. van der Molen T, Østrem A, Stallberg B, Østergaard MS, Singh RB. International Primary Care Respiratory Group (IPCRG) Guidelines: management of asthma. Prim Care Resp J 2006;15:35-47. http://dx.doi.org/10.1016/j.pcrj.2005.11.001

5. Global Initiative for Asthma (GINA). Global strategy for asthma management and prevention. 2007.

6. National Collaborating Centre for Chronic Conditions. Chronic obstructive pulmonary disease. Management of chronic obstructive pulmonary disease in adults in primary and secondary care. National Institute for Clinical Excellence. 2004.

7. British Thoracic Society and Scottish Intercollegiate Guidelines Network. British
Guideline on the management of asthma. A national clinical guideline. 2008.

8. Yawn BP, Enright PL, Lemanske RF, et al. Spirometry can be done in family physicians' offices and alters clinical decisions in management of asthma and COPD. Chest 2007;132:1162-8. http://dx.doi.org/10.1378/chest.06-2722

9. Poels PJ, Schermer TR, van Weel C, Calverley PM. Spirometry in chronic obstructive pulmonary disease. BMJ 2006;333:870-1. http://dx.doi.org/10.1136/bmj.38987.478727.80

10. Yawn BP, Wollan PC. Knowledge and attitudes of family physicians coming to COPD continuing medical education. Int J Chron Obstruct Pulmon Dis 2008 [published online 22 February 2008].

11. Bolton C, lonescu A, Edwards P, Faulkner T, Edwards S, Shale D. Attaining a correct COPD diagnosis in general practice. Respir Med 2005;99:493-500. http://dx.doi.org/10.1016/j.rmed.2004.09.015

12. Tinkelman DG, Price D, Nordyke RJ, Halbert RJ. COPD screening efforts in primary care: what is the yield? Prim Care Resp 2007;16:41-8.

13. Anthonisen NR, Connett JE, Kiley JP, et al. Effects of smoking intervention and the use of an inhaled anticholinergic bronchodilator on the rate of decline of FEV1. The Lung Health Study. JAMA 1994;272:1497-505. http://dx.doi.org/10.1001/jama.272.19.1497

14. Scanlon PD, Connett JE, Waller LA, Altose MD, Bailey WC, Buist AS. Smoking cessation and lung function in mild-to-moderate chronic obstructive pulmonary disease. The Lung Health Study. Am J Respir Crit Care Med 2000; 161(2 Pt 1):381-90.

15. Miller MR, Hankinson J, Brusasco V, et al. ATS/ERS Task Force: Standardisation of lung function testing series. Number 2. Standardisation of spirometry. Eur Respir J 2005,26:319-38. http://dx.doi.org/10.1183/09031936.05.00034805

16. Lin K, Watkins B, Johnson T, Rodriguez JA, Barton MB. Screening for Chronic Obstructive Pulmonary Disease Using Spirometry: Summary of the Evidence for the U.S. Preventive Services Task Force. Ann Intern Med 2008;148:60520-213.

17. Wilt TJ, Niewoehner D, Kim C, et al. Use of spirometry for case finding, diagnosis, and management of chronic obstructive pulmonary disease (COPD). Evid Rep Technol Assess (Summ) 2005; 121:1-7.

18. Stratelis G, Mölstad $S$, Jakobsson P, Zetterström $O$. The impact of repeated spirometry and smoking cessation advice on smokers with mild COPD. Scand J Prim Health Care 2006;24:133-9. http://dx.doi.org/10.1080/ 02813430600819751

19. Walker PP, Mitchell P, Diamantea F, Warburton CJ, Davies L. Effect of primarycare spirometry on the diagnosis and management of COPD. Eur Respir J 2006; 28: 945-52. http://dx.doi.org/10.1183/09031936.06.00019306

20. Price DB, Tinkelman DG, Nordyke RJ, et al. Scoring system and clinical application of COPD diagnostic questionnaires. Chest 2006;129:1531-9. http://dx.doi.org/10.1378/chest.129.6.1531

21. Ferguson GT, Enright PL, Buist AS, Higgins MW. Office spirometry for lung health assessment in adults: A consensus statement from the National Lung Health Education Program. Chest 2000;117:1146-61. http://dx.doi.org/10.1378/chest.117.4.1146

22. Celli BR, Cote CG, Marin JM, et al. The body-mass index, airflow obstruction, dyspnea, and exercise capacity index in chronic obstructive pulmonary disease. $N$ Engl J Med 2004; 350(10): 1005-12. http://dx.doi.org/ 10.1056/NEJMoa021322

23. Jones $R$, Hyland $M$, Harding S, Price $D$. The derivation of a new index of severity for COPD patients, the DOSE index: MRC dyspnea scale, airflow obstruction, smoking status and exacerbations. European Respiratory Society 2007: Abstract 1601;252S. Available at: https://www.ersnetsecure.org/public/prg_ congres.abstract?ww_i_presentation $=29516$

24. Jones R, Chavannes N, Kida K, Donaldson G, Hyland M, Price D. The DOSE index predicts quality of life, health care consumption and mortality. European Respiratory Society 2007: Abstract 1602;252S. Available at: https://www.ersnetsecure.org/public/prg_congres.abstract?ww_i_presentation $=29517$ 
25. Juniper EF, O'Byrne PM, Guyatt GH, et al. Development and validation of a questionnaire to measure asthma control. Eur Respir J 1999;14:902-90.

26. Lange P, Parner J, Schnohr P, Jensen G. Copenhagen City Heart Study: longitudinal analysis of ventilatory capacity in diabetic and nondiabetic adults. Eur Respir J 2002;20:1406-12. http://dx.doi.org/10.1183/ 09031936.02 .00050502

27. Ramirez LC, Dal Nogare A, Hsia CCW, et al. Relationship between diabetes control and pulmonary function in insulin dependent diabetes mellitus. Am J Med 1991;91:371-6. http://dx.doi.org/10.1016/0002-9343(91)90154-P

28. Walter RE, Beiser A, Givelber RJ, O'Connor GT, Gotlieb DJ. Association between glycemic state and lung function: the Framingham Heart Study. Am J Respir Crit Care Med 2003;167:911-16.

29. Ford ES, Mannino DM. Prospective association between lung function and the incidence of diabetes from National Health and Nutritional Examination Survey Epidemiological Follow-up Study. Diabetes Care 2004;27:2966-70. http://dx.doi.org/10.2337/diacare.27.12.2966

30. Davis WA, Knuiman M, Kendall P, Grange V, Davis TM. Glycemic exposure is associated with reduced pulmonary function in type 2 diabetes: the Fremantle Diabetes Study. Diabetes Care 2004;27:752-7. http://dx.doi.org/ 10.2337/diacare.27.3.752

31. Litonjua AA, Lazarus R, Sparrow D, Demolles D, Weiss ST. Lung function in type 2 diabetes: the Normative Ageing Study. Resp Med 2005;99:1583-90.

32. Yeh HC, Punjabi NM, Wang NY, et al. Vital capacity as a predictor of incident in type 2 diabetes: the Atherosclerosis Risk in Community study. Diabetes Care 2005;28:1472-79. http://dx.doi.org/10.2337/diacare.28.6.1472

33. Lawlor DA, Ebraham S, Smith GD. Association of measures of lung function with insulin resistance and type 2 diabetes: findings from the British Women's Heart and Health Study. Diabetologia 2004;47:195-203. http://dx.doi.org/10.1007/s00125-003-1310-6

34. Gorecka D, Bednarek M, Nowinski A, Puscinska E, Goljan-Geremek A, Zielinski J. Diagnosis of airflow limitation combined with smoking cessation advice increases stop-smoking rate. Chest 2003;123:1916-23. http://dx.doi.org/10.1378/chest.123.6.1916

35. Fletcher $\mathrm{C}$, Peto R. The natural history of chronic airflow obstruction. BMJ 1977;1:1645-8. http://dx.doi.org/10.1136/bmj.1.6077.1645

36. Parkes G, Greenhalgh T, Griffin M, et al. Effect on smoking quit rate of telling patients their lung age: the Step2quit randomized controlled trial. BMJ 2008; 336:598-600. http://dx.doi.org/10.1136/bmj.39503.582396.25

37. US Preventive Services Task Force. Screening for Chronic Obstructive Pulmonary Disease Using Spirometry: U.S. Preventive Services Task Force Recommendation Statement. Ann Intern Med 2008;148:529-534.

38. Miravitlles M, Anzueto A. Insights into interventions in managing COPD patients: lessons from the TORCH and UPLIFT studies. Int J Chron Obstruct Pulmon Dis 2009;4:185-201.

39. Derom E, van Weel C, Liistro G, et al. Primary care spirometry. Eur Respir J 2008;31:197-203. http://dx.doi.org/10.1183/09031936.00066607

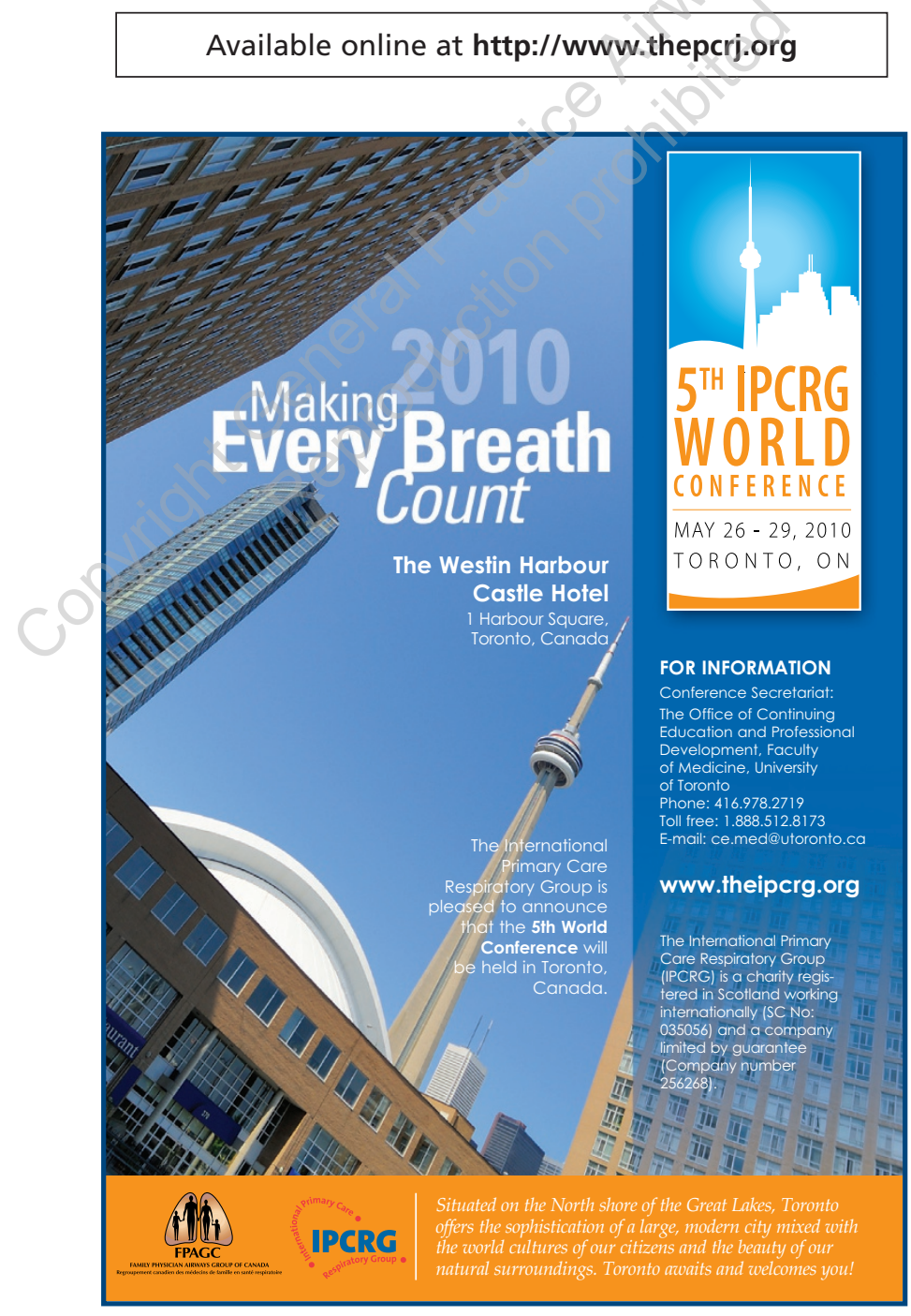

